\title{
Regulation of insulin-regulated membrane aminopeptidase activity by its C-terminal domain
}

Ascher, David; Cromer, Brett; Morton, Craig; Volitakis, I; Cherny, R; Albiston, Anthony; CHAl, S https://researchrepository.rmit.edu.au/esploro/outputs/9921858259701341/filesAndLinks?institution=61RMIT_INST\&index=null

Ascher, D., Cromer, B., Morton, C., Volitakis, I., Cherny, R., Albiston, A., CHAl, S., \& Parker, M. (2011).

Regulation of insulin-regulated membrane aminopeptidase activity by its C-terminal domain.

Biochemistry, 50(13), 2611-2622. https://doi.org/10.1021/bi101893w

Document Version: Accepted Manuscript

Published Version: https://doi.org/10.1021/bi101893w

Repository homepage: https://researchrepository.rmit.edu.au

(c) 2011 American Chemical Society

Downloaded On 2023/04/26 19:56:01 +1000 


\section{INSIGHTS INTO THE REGULATION OF INSULIN-REGULATED MEMBRANE}

\section{AMINOPEPTIDASE*}

David B. Ascher ${ }^{1}$, Brett A. Cromer ${ }^{1}$, Craig J. Morton ${ }^{1}$, Irene Volitakis ${ }^{2,3}$, Robert A. Cherny ${ }^{2,3}$, Anthony L. Albiston ${ }^{4}$, Siew Yeen Chai ${ }^{4}$, and Michael W. Parker ${ }^{1,5}$

From the Centre for Structural Neurobiology and Biota Structural Biology Laboratory, St. Vincent's Institute, 9 Princes Street, Fitzroy, Victoria 3065, Australia ${ }^{1}$, Department of Pathology, The University of Melbourne, Victoria 3010, Australia ${ }^{2}$, The Mental Health Research Institute of Victoria, Parkville,

Victoria, 3052, Australia $^{3}$, Howard Florey Institute of Experimental Medicine and Physiology, The

University of Melbourne, Parkville, Victoria 3010, Australia ${ }^{4}$, Department of Biochemistry and Molecular Biology, Bio21 Molecular Science and Biotechnology Institute, The University of Melbourne,

30 Flemington Road, Parkville, Victoria 3010, Australia ${ }^{5}$

Running head: Insulin-regulated aminopeptidase mechanism

Address correspondence to: Michael W. Parker, St. Vincent's Institute, 9 Princes Street, Fitzroy, Victoria 3065, Australia, Tel.: 61-3-9288-2499; Fax: 61-3-9416-2676; E-mail: mparker@svi.edu.au

Present address: Brett A. Cromer, Howard Florey Institute, University of Melbourne, Victoria 3010, Australia

Development of inhibitors of insulinregulated aminopeptidase (IRAP), a membrane-bound zinc metallopeptidase, is a promising approach for the discovery of drugs to treat memory loss such as that associated with Alzheimer's disease. There is, however, no consensus in the literature on the mechanism by which inhibition occurs. Sequence alignments, secondary structure predictions and homology models based on the structures of recently determined related metallopeptidases suggest that the extracellular region consists of four domains. Partial proteolysis and mass spectrometry have confirmed some of the domain boundaries. We have produced purified recombinant fragments of IRAP based on these data and examined their kinetic and biochemical properties. Full length extracellular constructs assemble as dimers which are not disrupted by reducing agents, metal chelators or inhibitor binding. Different fragments have the ability to dimerize suggesting an extended dimer interface. Only recombinant fragments containing the proposed domains 1 and 2 possess aminopeptidase activity and bind the radiolabelled inhibitor, Ang IV. Fragments lacking domains 3 and 4 possess reduced activity although they still bound a range of inhibitors with the same affinity as longer length fragments. In the presence of Ang IV, IRAP is resistant to proteolysis suggesting significant conformational changes occur on binding of the inhibitor. We show that IRAP has a second $\mathrm{Zn}^{2+}$ binding site, not associated with the catalytic region, which is lost upon binding Ang IV. Modulation of activity caused by domains 3 and 4 is consistent with a conformational change regulating access to the active site of IRAP.

Insulin-regulated aminopeptidase (IRAP), also known as the $\mathrm{AT}_{4}$ receptor (1) or oxytocinase (2), plays a number of important but diverse roles in the body. While it was first implicated in the regulation of parturition through the proteolysis of the uterogenic peptide oxytocin, IRAP has subsequently been implicated in diabetes, the immune system and memory (3-5). IRAP is normally located in intracellular GLUT4 vesicles where it translocates to the plasma membrane in response to insulin. It is then rapidly internalized back into the post-endosomal GLUT4 vesicles (6). A range of ligands originally described as $\mathrm{AT}_{4}$ agonists, including Angiotensin IV (Ang IV) and LVV-hemophin-7 (LVV-H7), have subsequently been shown to inhibit the aminopeptidase activity of IRAP $(1,7,8)$. When administered intracranially these inhibitors have been shown to greatly enhance memory and cognitive function in normal rodents $(9,10)$ and reverse memory deficits 
in animal models of amnesia (11-14). These effects are likely to be mediated through the inhibition of degradation of endogenous neural promnestic peptides since several IRAP substrates such as vasopressin $(15,16)$, CCK-8 (17-22), oxytocin (23) and somatostatin $(24,25)$ have been shown to facilitate learning and memory in animal models (see (26) for a review). A number of alternative mechanisms to explain the cognitive improvement have also been proposed (27). The importance of IRAP in memory has been strikingly demonstrated recently with the report of novel and highly specific small molecule inhibitors (28). When tested in vivo the compounds were able to improve cognitive function in animals. This work provides compelling evidence for the role of IRAP in improving cognitive function through inhibition of its enzymatic activity.

IRAP belongs to the M1 family of zinc metallopeptidases (2). This class of enzymes is characterized by two common structural features: a $\mathrm{Zn}^{2+}$-binding motif $\operatorname{HEXXH}(\mathrm{X})_{18}-\mathrm{E}$ and an exopeptidase motif GXMEN. IRAP is a type II membrane-spanning protein with an extracellular catalytic site. The intracellular region contains many serines and threonines in phosphorylation consensus sequences while the extracellular region contains $18 \mathrm{~N}$-linked glycosylation sites as well as a putative cleavage site $\left(\mathrm{F}^{154} / \mathrm{A}^{155}\right)$ for release of the extracellular region of IRAP $(29,30)$ with ADAM12 reported to be responsible for this cleavage (31). Several groups have looked at IRAP inhibition using a range of techniques and have proposed three different mechanisms of inhibition. Firstly, based upon the kinetics of inhibition, we have previously proposed that inhibitors such as Ang IV inhibit IRAP activity directly through competitive inhibition $(7,32)$. Secondly, it has also been reported that Ang IV interacts with a juxta-membrane site of IRAP and that Ang IV may use an allosteric mechanism to modulate IRAP activity (33). Finally, it has been reported that Ang IV only binds with high affinity to the $\mathrm{Zn}^{2+}$-depleted apoenzyme and may inhibit IRAP activity by stabilizing an inactive apoenzyme form (34-36). While these conclusions are not necessarily mutually exclusive, it highlights that further work is required to understand the mechanism behind Ang IV modulation of IRAP activity.
The extracellular portion of members of the M1 aminopeptidase family can be divided into two main sub-regions: an N-terminal region that contains the consensus active site residues and a C-terminal region of unknown function $(37,38)$. It has been postulated that the $\mathrm{C}$-terminal region acts as a molecular chaperone and is required for the correct processing and localization of the M1 members, as truncations lacking this region are not processed correctly (38). While the C-terminal region in aminopeptidase $\mathrm{A}$ (APA) is not required for activity (38), Kumar et al. showed that small truncations of between 4-10 distal carboxyl terminal amino acid residues from two bacterial M1 aminopeptidases greatly reduced activity of the enzymes (39). Recently the structures of the aminopeptidase Tricorn Interacting Factor F3 and the related aminopeptidase N (APN) from E. coli and $N$. meningitides were determined (40-42). These structures suggested that the C-terminal region may play an important role in regulating activity, with an open conformation that can accept a substrate and a closed conformation that is likely to be catalytically active. It has also been shown that interactions between the two domains can alter activity (43). These results are suggestive of a potential role for the C-terminal region in regulating the activity of some M1 aminopeptidases.

Considering the wide-ranging effects mediated by IRAP and its inhibitors, an understanding of IRAPs biochemical mechanism of action and inhibition will help guide the design of more potent physiologically stable inhibitors. Here we define the essential regions of IRAP required for aminopeptidase activity, inhibition and regulation leading to a model that rationalizes these and previously published observations.

\section{Experimental Procedures}

Bioinformatics analyses- Sequence alignments of analogous and homologous sequences identified by psi-BLAST (44) were performed using ClustalW (45) and Fugue (46) and viewed using ALSCRIPT (47) and ESPRIPT (48). Secondary structure predictions were performed using a variety of programs including APSSP2 (49), JUFO (50), PHDSec (51), PRED-TMR2 (52), PsiPred (53) and SSpro (54). Potential transmembrane regions were predicted using HMMTOP (55), 
PredictProtein, SOSUI (56), TMAP (57), TMHMM (58) and TMpred (59). A consensus result was recorded in each analysis where there was more than $70 \%$ agreement by all methods tested.

Expression and purification- Seven different constructs covering the entire extracelluar region were expressed in insect cells, secreted into the media and purified as described in detail elsewhere (Ascher et al., in preparation). Briefly, the boundaries chosen were based upon bioinformatics analysis (Figs. 1 \& S1) and expressed with His and MBP-His tags followed by a TEV protease site for removal of the tags. Sitedirected mutagenesis was performed using the Stratagene QuikChange II XL Site-Directed Mutagenesis Kit according to the manufacturer's instructions. All constructs were sequenced by the Sequencing Facility, Pathology Department, University of Melbourne. Following baculoviral expression, the media was concentrated and buffer exchanged into $500 \mathrm{mM} \mathrm{NaCl}, 100 \mathrm{mM}$ maltose, $25 \mathrm{mM}$ Tris- $\mathrm{HCl}, 20 \mathrm{mM}$ imidazole $\mathrm{pH}$ 6.8-7.2, and batch purified using Qiagen Ni-NTA Superflow resin. The tags were removed from the constructs by incubation with recombinant Histagged TEV. The tags and tagged-TEV were then removed by incubation with Ni-NTA resin. The purified proteins were dialysed into $25 \mathrm{mM}$ Tris$\mathrm{HCl} \mathrm{pH}$ 6.8-7.2, $150 \mathrm{mM} \mathrm{NaCl}$ and concentrated. The individual domain constructs were also expressed with a GST tag for use in pull-down assays. The majority of these latter constructs were incorrectly processed; the fractions containing correctly secreted protein were purified by incubation with GSH resin from Novagen. A range of mutations were introduced into constructs 6 and 7 (Fig. 1) using the QuickChange Site Directed Mutagenesis kit (Stratagene).

Size exclusion chromatograph- The approximate molecular mass and oligmerization state of the purified proteins were estimated by size exclusion chromatography using a GE Akta Express fitted with a Sephedex 200 10/300HL column and using a mobile phase of $25 \mathrm{mM}$ Tris- $\mathrm{HCl} \mathrm{pH} 7.1,150$ $\mathrm{mM} \mathrm{NaCl}$. Calibration was performed using the High MWt Calibration Kit from GE Healthcare $\left(r^{2}\right.$ $>0.99$ ).

Dynamic light scattering- The oligmerization states of the purified constructs were analyzed by dynamic light scattering using a Malvern
Instruments Zetasizer Nano ZS. The GE Healthcare High MWt Calibration Kit was used for standards.

Pull-downs- For pull-down assays purified Histagged D1+D2 and GST-tagged D4 were bound to Ni-NTA and glutathione resin respectively. Unbound protein was washed off in $150 \mathrm{mM}$ $\mathrm{NaCl}, 20 \mathrm{mM}$ imidazole and $25 \mathrm{mM}$ Tris- $\mathrm{HCl} \mathrm{pH}$ 7.2. The resins were then incubated at $4{ }^{\circ} \mathrm{C}$ for $1-2$ hours with untagged $\mathrm{D} 1+\mathrm{D} 2$ or D4. As controls, untagged D1+D2 and D4 were also incubated with Ni-NTA and glutathione resin alone to ensure they did not interact directly with the resins (data not shown). Unbound protein was once again washed off in $150 \mathrm{mM} \mathrm{NaCl}, 20 \mathrm{mM}$ imidazole and 25 $\mathrm{mM}$ Tris $\mathrm{pH} 7.2$, and the beads were resuspended in $1 \times$ SDS protein sample buffer and analyzed on a $4-12 \%(\mathrm{w} / \mathrm{v})$ acrylamide gel.

Enzyme activity and inhibition assay- The catalytic activity of the recombinant products was determined by the hydrolysis of a synthetic fluorogenic substrate, L-leucine-4methylcoumaryl-7-amide (MCA), in a microtitre plate assay (as described in reference (60). The potency of each inhibitor was determined over a range of concentrations and at multiple substrate concentrations, with each concentration assayed in triplicate. The $k_{\text {cat }}$ and $K_{\mathrm{m}}$ values were calculated using Michaelis-Menten kinetics by non-linear regression using the GraphPad Prism program (GraphPad Software Inc., San Diego, CA). The inhibition data were fitted by GraphPad Prism using non-linear regression to equations for competitive $(\mathrm{Y}=\mathrm{Vmax} * \mathrm{X} /(\mathrm{Kmapp}+\mathrm{X}))$, noncompetitive $\quad(\mathrm{Y}=\mathrm{Vmaxinh} * \mathrm{X} /(\mathrm{KM}+\mathrm{X}))$, uncompetitive $\quad(\mathrm{Y}=\mathrm{Vmax} A \mathrm{pp} * \mathrm{X} /(\mathrm{KmApp}+\mathrm{X}))$ and mixed $(\mathrm{Y}=(\mathrm{Vmax} * \mathrm{X}) /(\mathrm{Kmapp}$ $\left.\left.+\left(\mathrm{X}^{*}(1+(\mathrm{I} /(\mathrm{A} * \mathrm{Ki})))\right)\right)\right)$ inhibition models. The inhibition constants were also determined from the linear secondary plots (data not shown). The temperature stability of each construct was determined by incubating the purified protein at the temperature of interest $\left(4-55^{\circ} \mathrm{C}\right)$ overnight. The activity was then measured as described above. The $\mathrm{pH}$ sensitivity of each construct was determined by dialyzing the purified protein into the $\mathrm{pH}$ of interest $(\mathrm{pH} 4-10)$ using Slide-A-Lyzer Mini Dialysis Units (Pierce) and the activity measured as described above. Each replicate (n) is a separate protein preparation measured in triplicate. All analyses were repeated a minimum 
of three times $(n=3)$. Significant differences were examined by one-way Anova with Tukey posttest.

Radioligand binding assay- The published method for determining competitive and saturation kinetics of IRAP (61) was modified to take account that this study has used purified protein rather than partially purified membrane preparations. Purified protein in $25 \mathrm{mM}$ Tris- $\mathrm{HCl}$ $\mathrm{pH} 7.2,150 \mathrm{mM} \mathrm{NaCl}$ was incubated with ${ }^{125} \mathrm{I}-$ $\mathrm{Nle}^{1}$-Ang IV (specific activity of $2175 \mathrm{Ci} / \mathrm{mmol}$ ) in the presence of $100 \mu \mathrm{M} 1,10$-phenanthroline. For saturation binding studies up to $10 \mathrm{pmol}$ of purified protein was incubated with increasing

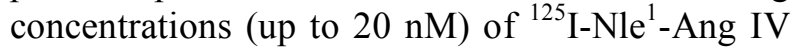
for $2 \mathrm{~h}$ at $37^{\circ} \mathrm{C}$ and non-specific binding was determined in the presence of $10 \mu \mathrm{M}$ of unlabelled Ang IV. For competition binding studies, $5 \mathrm{pmol}$ of purified protein was incubated with $0.5 \mu \mathrm{Ci} / \mathrm{mL}$ ${ }^{125} \mathrm{I}_{-\mathrm{Nle}}{ }^{1}$-Ang IV and increasing concentrations of unlabelled $\mathrm{Nle}^{1}$-Ang IV and Ang IV for $2 \mathrm{~h}$ at $37^{\circ} \mathrm{C}$. For both competition and saturation binding studies, bound and free radioligand were separated using illusra MicroSpin G-25 columns (GE Healthcare), pre-equilibrated in the binding buffer. The radioligand binding data was analyzed on an iterative, model-fitting program on GraphPad Prism (GraphPad Software Inc., San Diego, CA, USA) with $K_{\mathrm{d}}$ and $\mathrm{B}_{\max }$ derived using the equation $\mathrm{Y}=\mathrm{B}_{\max } * \mathrm{X} /\left(K_{\mathrm{d}}+\mathrm{X}\right)$ and $K_{\mathrm{i}}$ derived using the equation $K_{\mathrm{i}}=\mathrm{IC}_{50} /\left(1+[\mathrm{S}] / K_{\mathrm{d}}\right)$. Each replicate (n) is a separate protein preparation measured in triplicate. All analyses were repeated a minimum of three times $(n=3)$ and significant differences were examined by one-way Anova with Tukey post-hoc test.

Proteolytic fragmentation- Protease digestions by proteinase $\mathrm{K}$, chymotrypsin and trypsin were conducted in $50 \mathrm{mM}$ Tris- $\mathrm{HCl}$ buffer $\mathrm{pH}$ 7.2, containing $150 \mathrm{mM} \mathrm{NaCl}$ in the presence and absence of $500 \mathrm{nM}$ Ang IV at $37^{\circ} \mathrm{C}$ for 2 hours. The reactions were stopped by either the addition of sample loading buffer and boiling for $5 \mathrm{~min}$ prior to analysis by SDS/PAGE or by the addition of PMSF to a final concentration of $0.5 \mathrm{mM}$ for proteinase $\mathrm{K}$ and chymotrypsin digests or soybean trypsin inhibitor for trypsin digests.

ESI-MS and TOF-MS- Proteolyzed fragments, obtained by partial trypsin proteolysis, were deglycosylated using PNGaseF in order to obtain adequate sequence coverage. The Sigma-Aldrich
Trypsin Profile IGD Kit was then used to generate tryptic peptides for MS analysis. Samples were run on an Agilent 6510 Q-TOF LC/MS using a C18 column to help separate peptides and an Agilent 6340 Ion Trap LC/MS using an Agilent HPLC chip (40 nl enrichment column, $150 \mathrm{~mm} \times 75 \mu \mathrm{m}$ analytical column with $5 \mu \mathrm{m} \mathrm{C18}$ Zorbax resin). Experimental peptide masses and $\mathrm{ms} / \mathrm{ms}$ fragmentation were then compared to the predicted peptide masses by the Expasy webtool PeptideMass (http://au.expasy.org/tools/peptidemass.html, (62)).

Inductively coupled plasma mass spectrometry (ICP-MS) for analysis of metal content- Samples $(200 \mu \mathrm{g})$ were incubated, with and without Ang IV $(0,100,250,500$ and $1000 \mathrm{nM})$, at room temperature for one hour (for comparisons only 0 and $250 \mathrm{nM}$ data are presented). The protein was then isolated by running through an Illusra MicroSpin G-25 column (GE Healthcare), preequilibrated in the sample buffer, and then concentrated. Samples (at $1 \mathrm{mg} / \mathrm{ml}$ ) were diluted in a $1 \%(\mathrm{v} / \mathrm{v}) \mathrm{HNO}_{3}$ solution for analysis by ICPMS. ICP-MS was performed using an Ultramass 700 instrument (Varian, Victoria, Australia). Levels of $\mathrm{Fe}$ and $\mathrm{Cu}$ ions measured were not significant in any of the samples tested. Each replicate is of a different protein preparation and significant differences were analyzed by one-way Anova with Tukey post-test.

Molecular modeling of IRAP- The crystal structures of two closely related M1 aminopeptidases have been determined: Thermoplasma acidophilum Tricorn Interacting Factor F3 (PBD code 1Z5H, (40)), and Escherichia coli aminopeptidase N (APN) (PBD code 2DQ6, (41)). Whilst the overall similarity between the sequences is low (ranging between 21 and $25 \%$ pairwise sequence identity, $38-46 \%$ sequence similarity to IRAP), the region immediately surrounding the active site residues, including the HEXXH and GXMEN motifs, is relatively well conserved $(23-35 \%$ pairwise sequence identity, $42-55 \%$ sequence similarity to IRAP) and some significant sequence similarity can be seen in the C-terminal regions (eg. $~ 33 \%$ similarity between Tricorn vs IRAP). A sequence alignment of several different members of the M1 aminopeptidase family along with predicted secondary structure was used to guide model building (Fig. S1). The models (open and closed 
states) were built using Swiss PDB Viewer (63) and minimized in Sybyl under the Tripos forcefield (Tripos, St. Louis, MO). $\mathrm{Zn}^{2+}$ was manually added to the active site motif after comparison with the $\mathrm{Zn}^{2+}$-bound structures of aminopeptidase $\mathrm{N}$ and Tricorn Interacting Factor F3 indicated the conformation of residues in the $\mathrm{Zn}^{2+}$ binding motif was identical amongst the proteins. The quality of the models were analyzed with Verify3D (64) which indicated that the models were of good quality (data not shown).

Statistical analyses- All statistical analyses were performed using using the GraphPad Prism program (GraphPad Software Inc., San Diego, CA). Each replicate is of a separate protein preparation measured three times.

\section{RESULTS}

Design of constructs. We predicted that IRAP is composed of six distinct regions based upon sequence alignments, domain and secondary structure prediction programs (Figs. 1B \& S1): a cytoplasmic region (residues 1-110), a typical $\alpha$ helical trans-membrane region (TM, residues 111133) followed by a small juxtamembrane region $(\mathrm{JxM})$ of undefined structure, a $\beta$-sheet region (D1, 171-365) and two $\alpha$-helical regions (D2, residues 365-615 and D4, residues 704-1025) separated by another $\beta$-sheet region (D3, 615-704). $\mathrm{D} 1+\mathrm{D} 2$ constitute the catalytic domains which contain the $\operatorname{HEXXH}(X)_{18} E \mathrm{Zn}^{2+}$ binding motif and the GAMEN exopeptidase motif. Eight distinct constructs were designed based upon this breakdown (Fig. 1). These were successfully expressed in insect cells, using baculovirus, and all extracellular constructs were efficiently secreted into the media, in contrast to work on related enzymes in mammalian cells.

The crystal structures of three related zinc aminopeptidases have been determined: LTA4H (65), Tricorn Interacting Factor F3 (40) and APN $(41,42)$. Based upon these structures we have generated several molecular models of the extracellular region of IRAP. Initially we had built a model of the catalytic region on the crystal structure of LTA4H $(28,66)$. At the time the Cterminal region could not be modelled due to very low sequence similarity: sequence alignments suggested that LTA4H lacked D3 and a significant proportion of D4. Following the publication of the crystal structures of Tricorn Interacting Factor F3 and $E$. coli APN we were able to model the entire extracellular region of IRAP in open and closed states (Figs. 1B \& C). While the secondary structural alignment between these two extracellular region models was consistent, the relative positioning of the individual domains was quite distinct. The models of the extracellular region of IRAP are limited by the fact the sequence similarity and hence reliability of the model decreases towards the $\mathrm{C}$-terminal end of the molecule. Regardless, the homology models are consistent with the bioinformatics predictions of the different structural regions (D1-D4). All the models suggest that D1 and D2 form a tight interface while D3 and D4 form more distinct independent units.

IRAP extracellular region dimerizes and is comprised of separable stable domains. The purified constructs were analyzed by size exclusion chromatography (SEC) and dynamic light scattering, under native non-reducing conditions. The full length constructs eluted in a nearly homogeneous peak with a molecular weight consistent with a dimerized species of the recombinant IRAP (Table 1). Homodimer formation is one of the characteristic features of several membrane-bound members of the M1 family including APA (37), thyrotropin-releasing hormone-degrading ectoenzyme (TRH-DE) (67) and APN $(68,69)$. APA and TRH-DE form disulfide-linked homodimers in which the first cysteine residue in the extracellular region after the transmembrane domain is covalently bound to the same cysteine in the second monomer of the dimer. Therefore, we hypothesized that this might also be the case for IRAP. However the recombinant IRAP was completely dimerized even in the presence of $5 \mathrm{mM}$ DTT and also in constructs lacking the key cysteine residues (Cys134 and Cys141). This indicated that intermolecule disulfide formation is not required for dimerization of IRAP. To examine whether an inter-molecular disulfide is present, the purified constructs were run on SDS-PAGE in the presence and absence of DTT. For all purified extracellular constructs, a weak band with a molecular weight consistent with a dimer of IRAP was always observed. A difference between the samples run in the presence and absence of DTT was only observed in the constructs containing the juxta- 
membrane region (which contains $\mathrm{C} 134$ and C141), where in the absence of DTT a higher percentage of dimerized product was observed (data not shown). This disulfide, although not necessary for dimerization, is in a similar position to those in APA and TRH-DE where it is important for dimerization.

To examine any effect that binding of inhibitors may have on IRAP's dimerization, with potential implications for intracellular signaling, SEC was run in the presence of Ang IV. However, no differences were observed. As Ang IV has been proposed to only bind to the apo-form of IRAP $(34,35,70,71)$, the effects of the metal chelator 1,10-phenanthroline were also examined in the presence and absence of Ang IV. Once again the extracellular regions were predominantly dimers in the presence of 1,10-phenanthroline, with or without Ang IV.

D1+D2 and D4 formed homodimers independently of each other (Table 1), though a higher proportion of monomer was observed for the separate domains than observed with the full length construct. Thus D1+D2 and D4 appear to contain sufficient information on their own for homodimerization, suggesting an extended dimer interface between IRAP molecules.

When expressed for an extended period of time the His-tagged full length extracellular constructs were degraded in insect cell media to a stable protein approximately half the size of the full length construct. This fragment still contained its hexameric His tag, indicating that proteolysis was removing part of the C-terminal end of the protein. These observations were further explored by subjecting purified full length constructs to a range of proteolytic enzymes, which repeatedly showed that partial proteolysis yielded two stable fragments, one containing a His tag and the other without (Fig. S2). The boundaries of these stable fragments were examined by mass spectroscopy of in-gel tryptic digested peptides which suggested that the fragments corresponded to residues 168 to 560 and 718 to 1016 (Table S1). While tryptic peptides from the D3 region could be observed in the full length construct, they were not observed in the partially proteolyzed fragments suggesting that the His-tagged fragment corresponded to D1+D2 and the other fragment corresponded to D4. This proteolyzed protein, purified using the His-tag at the N-terminus, was more temperature and proteolytically stable than the catalytic domain construct containing D3 and was shown to also run as a dimer on SEC (Table 1).

Interaction between catalytic and C-terminal domains. There was some evidence of heterodimer formation, as judged by SEC, when purified $\mathrm{D} 1+\mathrm{D} 2$ and $\mathrm{D} 4$ fragments were mixed together. A small amount of a higher order complex was also evident by both SEC and commassie stain, consistent with a heterotetramer forming consisting of two D1+2 and two D4 fragments. Pull-down experiments were carried out to further analyze and characterize these complexes. Purified, untagged D1+D2 and D4 proteins were mixed with the equivalent Histagged proteins over the IMAC resin and the isolated proteins analyzed by SDS-PAGE. The hexa-His-tagged D1+D2 constructs were able to pull down purified untagged $\mathrm{D} 1+\mathrm{D} 2$ and D4 while, conversely, the GST-tagged D4 was able to pull down purified untagged D1+D2 and D4 (Fig. $\mathrm{S} 2$ ).

When partial proteolysis was performed in the presence of Ang IV, the intact extracellular region construct was resistant to proteolysis with less than $50 \%$ breakdown after $90 \mathrm{~min}$ compared to nearly complete proteolysis over the same time period in the absence of ligand. This is consistent with the hypothesis that upon binding of Ang IV the extracellular region of IRAP undergoes a conformational change making it less susceptible to proteolysis.

Catalytic domain is sufficient for catalytic activity and Ang IV inhibition. We predicted that $\mathrm{D} 1+\mathrm{D} 2$ alone would contain all of the structural information necessary for activity, based upon sequence comparisons to other M1 aminopeptidases (Fig. S1), and thus all constructs containing $\mathrm{D} 1+\mathrm{D} 2$ should be active. Our data confirmed this hypothesis but also revealed that the specific activity of D2 was significantly lower than the entire extracellular region (Table 2). The $K_{\mathrm{m}}$ values for the synthetic substrate MCA of the full length extracellular region and D1+D2 alone were similar to previously reported values for partially purified IRAP preparations (7) indicating that they show approximately the same level of affinity for the substrate. The $V_{\max }$ of purified $\mathrm{D} 1+\mathrm{D} 2$, whether expressed individually or in the presence of D4, was significantly reduced in comparison to the full length construct. This 
suggests that the decrease in activity observed for the catalytic region alone is not due to an altered affinity for the substrate but rather is due to the catalytic rate. This could indicate a requirement for D4 for full activity (ie. D4 acts as an activator/regulator) or that a proportion of the population is inactive. The ligand binding Bmax for D1-2 (Table 1) is similar to the complete extracellular domain, demonstrating that the reduced enzyme activity of D1-2 is not due to a proportion of this construct being unfolded. $\mathrm{D} 1+\mathrm{D} 2$ was also much more temperature and $\mathrm{pH}$ sensitive than the entire extracellular region (data not shown).

The role of D4 in regulating the activity of IRAP was explored further by measuring the activity of D1+2 in the presence of D4. A small increase in the activity of D1+D2 was observed in the presence of D4, although not to the level found for the entire extracellular region construct (Table 2 ). This may be because of low stability of the $\mathrm{D} 1+\mathrm{D} 2$ and D4 hetero-dimer or the interaction of the domains as separate molecules being only a partial mimic of the intact protein. This suggests that D4 is required for increasing the stabilization and activity of D1+D2 and is consistent with the hypothesis that a conformational change of D4 upon binding of substrate may be involved in regulating the activity of $\mathrm{D} 1+\mathrm{D} 2$.

A surprising observation was that the presence of DTT substantially enhanced the activity of the full length extracellular constructs (Table 2) with $V_{\max }$ only slightly increased but a substantially lower $K_{\mathrm{m}}$ for the synthetic substrate MCA. This suggested that DTT was acting by increasing the affinity for the substrate rather than enhancing the rate of the reaction. By contrast this phenomenon could not be detected with the catalytic domain constructs indicating that the enhanced affinity seen in the presence of DTT required D3 and D4. An alternative reducing agent, 2-mercaptoethanol, was tested to clarify whether it is the reducing action of DTT that enhances the activity of the full length constructs. 2-Mercaptoethanol was able to increase the affinity of the full length extracellular constructs for MCA, though not to the same extent as DTT (data not shown). This weaker effect could be a result of DTT's additional metal chelation enhancing affinity or differences in their reducing properties, however it does suggest that the presence of a reducing agent does improve the affinity of IRAP for MCA, potentially through the disruption of an internal disulfide bond enhancing access of substrate to catalytic site. Analysis of the metal content of the full length constructs in the presence and absence of DTT or 2mercaptoethanol revealed the same $\mathrm{Zn}^{2+}$ ion content.

The entire extracellular region of IRAP was inhibited by both Ang IV and LVV-H7, giving $K_{\mathrm{i}}$ 's consistent with previously published values (Table 2) (7). Several of the constructs were designed to lack the juxta-membrane region previously proposed as the allosteric site responsible for inhibition (constructs 3 and 8) (33). Inhibition of these constructs, however, was observed to approximately the same order of magnitude as seen with the entire extracellular region (Table 2). This suggests that any allosteric binding site for Ang IV outside of D2 of IRAP is not important for inhibition. Kinetic modelling showed that, consistent with our previously published observations (7), Ang IV competitively inhibited the activity of both the full length extracellular region and the catalytic region $\left(\mathrm{R}^{2}=\right.$ 0.98) (data not shown).

We found that Ang IV only binds to constructs containing $\mathrm{D} 1+2$ as judged by binding of ${ }^{125} \mathrm{I}-$ labeled $\mathrm{Nle}^{1}$-Ang IV to each of the constructs (Table 1), consistent with our kinetic data showing that Ang IV is binding directly to the catalytic site. Specific binding of radioligand was only observed in the presence of chelator, as has previously been reported, leading to the conclusion that Ang IV only binds with high affinity to the apoenzyme (34-36). The presence of DTT was, however, able to improve the binding efficiency (by approximately 200\%) of the full length constructs but not the catalytic constructs (Fig 2B). To rule out any effect of iodination upon the binding properties of Ang IV, the ability of ${ }^{125}$ I-labeled $\mathrm{Nle}^{1}$-Ang IV to inhibit the catalytic activity of IRAP was examined. The iodinated $\mathrm{Nle}^{1}$-Ang IV did not show any significant difference in inhibition to the unlabeled Nle ${ }^{1}$-Ang IV. This does not necessarily indicate that Ang IV only binds to the apoenzyme but that we can only measure binding to the apoenzyme. This could be a reflection of different mechanisms of binding, that the removal of zinc is able to help further stabilize Ang IV binding and/or differences in binding affinity between the native (approx $100 \mathrm{nM}$ ) and 
apoenzyme (approx $10 \mathrm{nM}$ ) particularly as weaker affinity binding can easily be missed by radioligand binding experiments. Analysis of the binding curves showed no indication of cooperativity between the two monomers, with the caveat that the measurements were done in the absence of $\mathrm{Zn}^{2+}$ and so are not necessarily carried out under native conditions.

Identification of a second non-catalytic zinc site. ICP-MS was used to examine the $\mathrm{Zn}$ content in the purified protein and indicated that there were $2 \mathrm{Zn}^{2+}$ ions per monomer in the full length extracellular construct (Table 1). This was surprising as only one $\mathrm{Zn}$ binding site had been previously identified (72). It is likely, however, that the second site was missed because there is no second consensus zinc binding sequence and, unlike here, the protein was expressed and purified without the addition of $\mathrm{Zn}^{2+}(72)$. The results reported by Matsumoto and colleagues (72) indicate that they may actually have had partial occupancy at this second site, as they obtained a ratio of 1.3 molecules of $\mathrm{Zn}^{2+}$ per monomer of IRAP. The models of IRAP were then uploaded to the Stanford Feature Metal Scan analysis model (73) that correctly identified the catalytic zinc binding site in the models of both the open and closed form, and predicted another potential zinc binding site towards the $\mathrm{C}$-terminus of the open model, with two potential sets of co-ordinating residues consisting of E825, C828 and $\mathrm{C} 835$; and H830, H934 and H938.

Examination of individual domain fragments indicated that one $\mathrm{Zn}^{2+}$ was associated with Domain 1 and 2 and the other with Domain 4, consistent with the Feature Metal Scan prediction. Upon the addition of excess Ang IV to the full length extracellular constructs one $\mathrm{Zn}^{2+}$ was lost. This was particularly interesting in light of Demaegdt et al, (34-36), and as we have shown here, who proposed that Ang IV only binds with high affinity to an IRAP apoenzyme lacking the catalytic $\mathrm{Zn}^{2+}$ ion. Loss of zinc, however, was not observed when Ang IV was added to the catalytic domain constructs (Table 1) suggesting that it is the $\mathrm{Zn}^{2+}$ associated with Domain 4 that was lost, consistent with the hypothesis that Domain 4 undergoes a conformational change following binding of the peptide inhibitor. The effect on zinc binding of other IRAP ligands and substrates was also explored. While not as marked as with Ang
$\mathrm{IV}$, a reduction of $75 \%$ of the second $\mathrm{Zn}^{2+}$ ion was observed for the full length extracellular constructs upon the addition of excess MCA, oxytocin and vasopressin, but no loss of zinc was seen from the catalytic domain constructs (data not shown).

To further explore this novel $\mathrm{Zn}^{2+}$ binding site, the $\mathrm{pH}$ dependence of $\mathrm{Zn}^{2+}$ binding by the purified constructs was examined. This revealed that the two sites had similar profiles, with all zinc lost at approximately $\mathrm{pH}$ of 6.2 ; approximately the normal pKa of histidine residues (Fig. 3A). This correlated with the $\mathrm{pH}$ sensitivity of the activity of the constructs as all enzyme function was lost around $\mathrm{pH}$ 6.2. While the catalytic $\mathrm{Zn}^{2+}$ binding motif has been well characterized and is known to contain two histidines, these data suggest that histidine residues are also involved in the chelation of the second zinc as well. Therefore, to identify some of the residues that are important in this second $\mathrm{Zn}^{2+}$ binding site we mutated all histidine residues to alanines, expressed and purified them from insect cells for biochemical analysis (Table S2). Six of the purified histidine mutated constructs showed significant changes in zinc content, His464Ala, His468Ala, H830Ala, His934Ala, His938Ala and His979Ala. Histidines 464 and 468 are the 'catalytic histidines' responsible for coordinating the zinc ion in the active site and have both been characterized previously (74). Consistent with their role in the active site, and the previous characterization of their mutation, the His464Ala and His468Ala both lacked any measurable aminopeptidase activity (Fig. 3B \& Table S2). The other four histidine mutations are clustered towards the distal end of Domain 4 (Fig. 3C). Inspection of both models of IRAP identified that this cluster of histidines could potentially bind a $\mathrm{Zn}^{2+}$ ion with coordinating ligands of H830, H934 and H938 or H934, H938 and H979. We consider the former more plausible, since it is consistent with the predictions from the Stanford Feature Metal Scan and the H979A mutation only resulted in a partial reduction in zinc binding, potentially though a localised allosteric affect. Mutations in any of these four decreased the amount of zinc bound, but did not dramatically alter the aminopeptidase activity.

\section{DISCUSSION}


In nearly all studies to date characterization of IRAP has been carried out on partially purified preparations from mammalian cells requiring membrane micelles for solubilization. The one notable exception is a study by Matsumoto and colleagues who purified a soluble form and showed that the full length extracellular region was able to dimerize and bind zinc in an approximately $1: 1$ stoichiometric ratio (72). In this work we have used insect cells to express a range of soluble recombinant IRAP truncations and mutants enabling a more detailed characterization of the enzyme, particularly with regards to behavior of the peptide inhibitor Ang IV. Ang IV has previously been shown to competitively inhibit IRAP's aminopeptidase activity with high nanomolar efficacy, although at levels much higher than the localized concentrations present in the brain. In addition radiolabelled Ang IV had only been shown to bind to IRAP, with low nanomolar efficacy, in the presence of metal chelators (36). These studies have led to questioning whether IRAP is the $\mathrm{AT}_{4}$ receptor responsible for the memory enhancing effects of Ang IV, particularly in light of recent in vivo studies attributing the memory enhancing effects to either aminopeptidase N, the AT1 receptor or cMET (75-77). One potential explanation for the requirement of metal chelators in the radioligand binding studies has been their protease inhibitory effects preventing the degradation of Ang IV in the partially purified membrane preparations. Thus studies of highly purified IRAP fragments could shed light on some of these questions.

All constructs containing the full length extracellular region were active and showed a similar affinity to Leu-MCA as previously published $(66,72)$. This provided reassurance that not only was the recombinant protein produced in the insect cell system active and behaving nearly identically to that produced from mammalian systems, but that the use of partially purified membrane preparations was a reliable way of analyzing IRAP activity. Furthermore, they were all inhibited by amastatin, bestatin, Ang IV and LVV-H7 to a similar extent to what had been previously published using partially purified membrane preparations. All these inhibitors were competitive, consistent with our previously published results using partially purified membrane preparations $(7,32)$.
A major finding here is that the catalytic region by itself $(\mathrm{D} 1+\mathrm{D} 2)$ is sufficient for both activity and inhibition by natural peptide antagonists. This is in contrast to work on APA, where it was shown that the C-terminal region was required for correct processing and activation of the catalytic region (38). Activity of the catalytic regions, however, was dramatically lower than for the full extracellular constructs, suggesting that the C-terminal region is still required for full activity. This is consistent with the work of Kumar and colleagues (39) who showed that removal of just a few amino acid residues from the C-terminal region of the bacterial M1 aminopeptidases Tricorn interacting factor F2 and Peptidase $\mathrm{N}$ greatly reduced activity. When co-expressed and purified with the C-terminal region, or the activity measured in the presence of the $\mathrm{C}$-terminal region, the catalytic constricts did show enhanced activity, although still not to the levels of the full length construct. We saw the same levels of both activity and inhibition by Ang IV in the presence and absence of the juxta-membrane region proposed as the binding site of Ang IV (33). This suggests that allosteric binding by Ang IV to a juxtamembrane region does not contribute to inhibition of IRAP. Furthermore, ${ }^{125} \mathrm{I}$-Ang IV was shown to bind in an approximately $1: 1$ ratio to all of the constructs containing the catalytic region, suggesting that there is only one Ang IV binding site and it is not located in the juxta-membrane region or in the $\mathrm{C}$ terminal region. This is consistent with the kinetic modeling that indicated Ang IV inhibition was competitive. However, as has been previously reported, we only observed Ang IV binding in the presence of divalent cation chelators.

Two members of the M1 family, APA and TRH-DE, have been shown to exist as disulfidelinked homodimers and for both enzymes the cysteine residue adjacent to the transmembrane domain was identified as the amino acid involved in the covalent bond $(37,67)$. In contrast, APN predominantly exists as a non-covalently-linked homodimer although the available crystal structures are of monomeric forms $(68,69)$. A number of studies have proposed that IRAP also exists as a homodimer $(72,78)$ and in the present study we have demonstrated that IRAP exists as a non-covalent homodimer by two different methods. While both the N-terminal and Cterminal regions formed dimers by themselves; 
this does not clearly explain the role of either region for dimerization in the native enzyme which will only be elucidated by obtaining a crystal structure for the intact extracellular domain. The functional importance of homodimerization (due to non-covalent interactions) for correct trafficking, processing, catalytic activity and signaling remains to be elucidated.

Limited proteolysis of the full length extracellular constructs revealed the formation of two stable proteins, one corresponding to Domain 1 and 2 and the other to Domain 4. However, neither of these fragments contained the interstitial $\beta$-sheet region (Domain 3). In the presence of Ang IV the full length constructs were significantly more resilient to proteolysis, consistent with the proposal that the two regions undergo a conformational change upon binding substrate/inhibitor. Because labeled Ang IV only bound in the presence of metal chelators, we also tested the proteolytic sensitivity of the full length constructs in the presence of 1,10-phenanthroline. Limited proteolysis resulted in the formation of two protein fragments irrespective of whether the metal chelator was present or not. However the addition of Ang IV did not reduce the sensitivity of IRAP to proteolysis in the presence of metal chelator. This suggests that Ang IV is binding in a different way in the presence of metal chelators and could explain the differences observed between the binding affinities and inhibition constants.

We observed that the presence of DTT not only increased affinity of the full extracellular region for ${ }^{125}$ I-Ang IV but also the activity measured by hydrolysis of MCA as well. This confirms a previous observation by Jarvis and colleagues (79). Previously metal ion modulation of IRAP has been shown to be important in both activity and Ang IV binding $(34,70)$. Therefore we considered that one possible explanation was that DTT might be chelating away metal ions in a similar manner to EDTA, thus increasing the affinity of IRAP for MCA and Ang IV. This would be consistent with other studies that have demonstrated an important role for metal ions in APA and APN activity (80-82). However, we showed that the bound zinc is not affected by addition of DTT and there are no are obvious ions in the IRAP preparation that might be chelated by the reducing agent. We also noted that 2mercaptoethanol resulted in an increase in binding affinity and activity, though not to the same extent as with DTT. An interesting hypothesis is that the redox state may play a role in the regulation of activity, with reduction in the GLUT4 postendosomal vesicles promoting maximal activity, which is lost over time while IRAP is on the cell surface in an oxidizing environment. This suggests that the compartment for maximal IRAP activity is intracellular, which may reflect its role in intracellular vesicles processing MHC class 1 antigens $(3,4)$. It also suggests that IRAP activity, and the related conformational changes, may play a role in trafficking, consistent with the signaling hypothesis of Ang IV memory enhancement (83). The open model of IRAP suggests that C828 and C835 could form a disulfide bond formation whereas such a bond is not possible in the closed model. This is consistent with DTT promoting conversion of the open state to the closed, active state.

Other groups have attempted to examine the role of the catalytic region of M1 aminopeptidases in isolation by expressing just the catalytic region in mammalian cells although they have not been able to observe activity $(38,84)$. Recently, however, it has been observed that the catalytic regions show some activity following either proteolysis of the intact aminopeptidases to generate the catalytic region or co-expression with the C-terminal region $(38,85)$. This suggests that the C-terminal region is essential for correct processing and folding in mammalian cells. By using baculovirus we have been able to overcome the requirement for the presence of the C-terminal region and have been able to express and purify the catalytic region of IRAP by itself and have observed proteolytic activity. Based on recent crystal structures it was proposed that conformational changes of the $\mathrm{C}$-terminal region of APN might regulate activity (41) where the extracellular region might adopt an 'open' and 'closed' conformation with the C-terminal region pivoting on a 'hinge'. As part of the mechanism of moving from an 'open' to 'closed' conformation Ito and coworkers (41) proposed that a small movement of catalytic residues occurred, generating a catalytically competent active site. In support of this, removal of just a few residues from the C-terminus of a couple of different M1 
aminopeptidases greatly reduced their activity (39). This may help explain the dramatically reduced activity of the catalytic region by itself, as it may require the conformational changes induced by the C-terminal region for full activity. The observation that DTT was able to enhance activity and Ang IV binding only in the presence of the Cterminus may be a result of this interaction between the $\mathrm{C}$-terminus and active site, as the effect was not observed on the catalytic region by itself. In support of the hypothesis that large conformational changes occur between the domains the full length extracellular construct was significantly more resilient to proteolysis in the presence of Ang IV.

When we examined the $\mathrm{Zn}^{2+}$ content in our purified extracellular region constructs we were surprised to find two $\mathrm{Zn}^{2+}$ bound per monomer, as it had been previously widely accepted that there was only one $\mathrm{Zn}^{2+}$ binding site. Analysis of our range of constructs revealed that the individual catalytic regions contained one $\mathrm{Zn}^{2+}$ per monomer, consistent with the consensus $\mathrm{Zn}^{2+}$ binding motif at the active site. We were further surprised that constructs containing the isolated C-terminal region also contained approximately one $\mathrm{Zn}^{2+}$ per monomer, particularly as there is no consensus $\mathrm{Zn}^{2+}$ binding motif, based on sequence analysis, nor has this second site been reported for any other M1 aminopeptidase before. In silico scanning of the models of IRAP revealed two potential coordination clusters, although these were only present in the model of the open form. One cluster consisted of cysteine 828 and 835, mentioned above. While this could provide a link between the regulatory effects of reducing agents in the presence of D4 and the changes in zinc binding in $\mathrm{D} 4$, this is unlikely since both were observed in the open sate, not the closed state. Mutation of His residues indicated the likely binding site for this second zinc was towards the distal end of Domain 4, with coordinating residues of $\mathrm{H} 830, \mathrm{H} 934$ and H938, although it was not needed for activity or substrate specificity. It is not clear whether this second site is a biologically relevant $\mathrm{Zn}$ binding site, although for the purposes of this study it proved a useful reporter. This study did reveal changes occurring in Domain 4 during binding. Interestingly, in the presence of Ang IV this second zinc ion is lost. This is further evidence suggesting that upon the binding of Ang IV, IRAP undergoes a conformational change. This is consistent with our partial proteolysis results showing that the extracellular constructs were more protease resistant in the presence of Ang IV, whereas in the absence of the inhibitor the constructs were readily degraded to separate $\mathrm{N}$ terminal and C-terminal products. The proteolytic fragmentation was similar to that seen in APA by Hesp and Hooper (37) and thus consistent with a common domain structure for the M1 aminopeptidases. There have been reports of other bivalent metal ions regulating the activity of M1 aminopeptidases including calcium in APA $(86,87)$, magnesium and calcium in IRAP and APN $(34,70,82)$, although none of these metals would be expected to bind to histidine residues.

The results presented in this work support the hypothesis that conformational changes allow the extracellular region of IRAP to adopt an 'open' or 'closed' conformation. The presence or absence of divalent metal ions appears to play a role in regulating these states. In the absence of Domain 4 these conformational changes are limited and result in greatly reduced activity consistent with Domain 4 being involved in the regulation of enzymatic activity.

\section{REFERENCES}

1. Albiston, A. L., McDowall, S. G., Matsacos, D., Sim, P., Clune, E., Mustafa, T., Lee, J., Mendelsohn, F. A., Simpson, R. J., Connolly, L. M., and Chai, S. Y. (2001) J Biol Chem 276, 48623-48626

2. Rogi, T., Tsujimoto, M., Nakazato, H., Mizutani, S., and Tomoda, Y. (1996) J Biol Chem 271, 56-61

3. Segura, E., Albiston, A. L., Wicks, I. P., Chai, S. Y., and Villadangos, J. A. (2009) Proc Natl Acad Sci U S A 106, 20377-20381 
4. Saveanu, L., Carroll, O., Weimershaus, M., Guermonprez, P., Firat, E., Lindo, V., Greer, F., Davoust, J., Kratzer, R., Keller, S. R., Niedermann, G., and van Endert, P. (2009) Science 325, 213-217

5. Albiston, A. L., Peck, G. R., Yeatman, H. R., Fernando, R., Ye, S., and Chai, S. Y. (2007) Pharmacol Ther 116, 417-427

6. Keller, S. R., Scott, H. M., Mastick, C. C., Aebersold, R., and Lienhard, G. E. (1995) J Biol Chem 270, 23612-23618

7. Lew, R. A., Mustafa, T., Ye, S., McDowall, S. G., Chai, S. Y., and Albiston, A. L. (2003) J Neurochem 86, 344-350

8. Lee, J., Mustafa, T., McDowall, S. G., Mendelsohn, F. A., Brennan, M., Lew, R. A., Albiston, A. L., and Chai, S. Y. (2003) J Pharmacol Exp Ther 305, 205-211

9. Wright, J. W., Miller-Wing, A. V., Shaffer, M. J., Higginson, C., Wright, D. E., Hanesworth, J. M., and Harding, J. W. (1993) Brain Res Bull 32, 497-502

10. Wright, J. W., Stubley, L., Pederson, E. S., Kramar, E. A., Hanesworth, J. M., and Harding, J. W. (1999) J Neurosci 19, 3952-3961

11. Wright, J. W., Clemens, J. A., Panetta, J. A., Smalstig, E. B., Weatherly, L. A., Kramar, E. A., Pederson, E. S., Mungall, B. H., and Harding, J. W. (1996) Brain Res 717, 1-11

12. Pederson, E. S., Harding, J. W., and Wright, J. W. (1998) Regul Pept 74, 97-103

13. Pederson, E. S., Krishnan, R., Harding, J. W., and Wright, J. W. (2001) Regul Pept 102, 147-156

14. Olson, M. L., Olson, E. A., Qualls, J. H., Stratton, J. J., Harding, J. W., and Wright, J. W. (2004) Peptides 25, 233-241

15. de Wied, D., Diamant, M., and Fodor, M. (1993) Front Neuroendocrinol 14, 251-302

16. Engelmann, M., Wotjak, C. T., Neumann, I., Ludwig, M., and Landgraf, R. (1996) Neurosci Biobehav Rev 20, 341-358

17. Dauge, V., and Lena, I. (1998) Neurosci Biobehav Rev 22, 815-825

18. Fink, H., Rex, A., Voits, M., and Voigt, J. P. (1998) Exp Brain Res 123, 77-83

19. Huston, J. P., Schildein, S., Gerhardt, P., Privou, C., Fink, H., and Hasenohrl, R. U. (1998) Peptides 19, 27-37

20. Sebret, A., Lena, I., Crete, D., Matsui, T., Roques, B. P., and Dauge, V. (1999) J Neurosci 19, 7230-7237

21. Voits, M., Hasenohrl, R. U., Huston, J. P., and Fink, H. (2001) Peptides 22, 1325-1330

22. Dauge, V., Pophillat, M., Crete, D., Melik-Parsadaniantz, S., and Roques, B. P. (2003) Neuroscience 118, 19-23

23. Tomizawa, K., Iga, N., Lu, Y. F., Moriwaki, A., Matsushita, M., Li, S. T., Miyamoto, O., Itano, T., and Matsui, H. (2003) Nat Neurosci 6, 384-390

24. Schettini, G., Florio, T., Magri, G., Grimaldi, M., Meucci, O., Landolfi, E., and Marino, A. (1988) Eur J Pharmacol 151, 399-407

25. DeNoble, V. J., Hepler, D. J., and Barto, R. A. (1989) Brain Res 482, 42-48

26. Gulpinar, M. A., and Yegen, B. C. (2004) Curr Protein Pept Sci 5, 457-473

27. Chai, S. Y., Fernando, R., Peck, G., Ye, S. Y., Mendelsohn, F. A., Jenkins, T. A., and Albiston, A. L. (2004) Cell Mol Life Sci 61, 2728-2737

28. Albiston, A. L., Morton, C. J., Ng, H. L., Pham, V., Yeatman, H. R., Ye, S., Fernando, R. N., De Bundel, D., Ascher, D. B., Mendelsohn, F. A., Parker, M. W., and Chai, S. Y. (2008) FASEB J 22, 4209-4217

29. Iwase, A., Nomura, S., and Mizutani, S. (2001) Arch Biochem Biophys 393, 163-169

30. Ofner, L. D., and Hooper, N. M. (2002) Placenta 23, 65-70

31. Ito, N., Nomura, S., Iwase, A., Ito, T., Kikkawa, F., Tsujimoto, M., Ishiura, S., and Mizutani, S. (2004) Biochem Biophys Res Commun 314, 1008-1013

32. Ye, S., Chai, S. Y., Lew, R. A., and Albiston, A. L. (2007) Biol Chem 388, 399-403

33. Caron, A. Z., Arguin, G., and Guillemette, G. (2003) Regul Pept 113, 9-15 
34. Demaegdt, H., Laeremans, H., De Backer, J. P., Mosselmans, S., Le, M. T., Kersemans, V., Michotte, Y., Vauquelin, G., and Vanderheyden, P. M. (2004) Biochem Pharmacol 68, 893-900

35. Demaegdt, H., Lenaerts, P. J., Swales, J., De Backer, J. P., Laeremans, H., Le, M. T., Kersemans, K., Vogel, L. K., Michotte, Y., Vanderheyden, P., and Vauquelin, G. (2006) Eur J Pharmacol 546, 19-27

36. Demaegdt, H., Lukaszuk, A., De Buyser, E., De Backer, J. P., Szemenyei, E., Toth, G., Chakravarthy, S., Panicker, M., Michotte, Y., Tourwe, D., and Vauquelin, G. (2009) Mol Cell Endocrinol 311, 77-86

37. Hesp, J. R., and Hooper, N. M. (1997) Biochemistry 36, 3000-3007

38. Rozenfeld, R., Muller, L., El Messari, S., and Llorens-Cortes, C. (2004) J Biol Chem 279, 43285-43295

39. Kumar, A., Bhosale, M., Reddy, S., Srinivasan, N., and Nandi, D. (2009) Biochimie 91, $1145-1155$

40. Kyrieleis, O. J., Goettig, P., Kiefersauer, R., Huber, R., and Brandstetter, H. (2005) J Mol Biol 349, 787-800

41. Ito, K., Nakajima, Y., Onohara, Y., Takeo, M., Nakashima, K., Matsubara, F., Ito, T., and Yoshimoto, T. (2006) J Biol Chem 281, 33664-33676

42. Nocek, B., Mulligan, R., Bargassa, M., Collart, F., and Joachimiak, A. (2008) Proteins 70, 273-279

43. Kumar, A., Reddy, S., Srinivasan, N., and Nandi, D. (2009) Protein Pept Lett 16, $415-$ 422

44. Altschul, S. F., and Koonin, E. V. (1998) Trends Biochem Sci 23, 444-447

45. Chenna, R., Sugawara, H., Koike, T., Lopez, R., Gibson, T. J., Higgins, D. G., and Thompson, J. D. (2003) Nucleic Acids Res 31, 3497-3500

46. Shi, J., Blundell, T. L., and Mizuguchi, K. (2001) J Mol Biol 310, 243-257

47. Barton, G. J. (1993) Protein Eng 6, 37-40

48. Gouet, P., Courcelle, E., Stuart, D. I., and Metoz, F. (1999) Bioinformatics 15, 305-308

49. Raghavan, G. P. S. (2002) CASP5 A-132

50. $\quad$ Meiler J., M. M., Zeidler A., Schmaeschke F. (2001) J. Mol. Model. 7, 360-369

51. Rost, B. (1996) Methods in Enzymology 266, 525-539

52. Pasquier, C., and Hamodrakas, S. J. (1999) Protein Eng 12, 631-634

53. Jones, D. T. (1999) J. Mol. Biol. 292, 195-202

54. J. Cheng, A. R., M. Sweredoski, P. Baldi. (2005) Nucleic Acids Research 33, 72-76

55. Tusnady, G. E., and Simon, I. (2001) Bioinformatics 17, 849-850

56. Hirokawa, T., Boon-Chieng, S., and Mitaku, S. (1998) Bioinformatics 14, 378-379

57. Milpetz, F., Argos, P., and Persson, B. (1995) Trends Biochem Sci 20, 204-205

58. Krogh, A., Larsson, B., von Heijne, G., and Sonnhammer, E. L. (2001) J Mol Biol 305, 567-580

59. Hofmann, K., and Stoffel, W. (1993) Biol. Chem. Hoppe-Seyler 374, 166

60. Kanaoka, Y., Takahashi, T., and Nakayama, H. (1977) Chem Pharm Bull (Tokyo) 25, 362-363

61. Moeller, I., Lew, R. A., Mendelsohn, F. A., Smith, A. I., Brennan, M. E., Tetaz, T. J., and Chai, S. Y. (1997) J Neurochem 68, 2530-2537

62. Wilkins, M. R., Lindskog, I., Gasteiger, E., Bairoch, A., Sanchez, J. C., Hochstrasser, D. F., and Appel, R. D. (1997) Electrophoresis 18, 403-408

63. Guex, N., and Peitsch, M. C. (1997) Electrophoresis 18, 2714-2723

64. Bowie, J. U., Luthy, R., and Eisenberg, D. (1991) Science 253, 164-170

65. Thunnissen, M. M., Andersson, B., Samuelsson, B., Wong, C. H., and Haeggstrom, J. Z. (2002) FASEB J 16, 1648-1650 
66. Ye, S., Chai, S. Y., Lew, R. A., Ascher, D. B., Morton, C. J., Parker, M. W., and Albiston, A. L. (2008) Biochem Cell Biol 86, 251-261

67. Papadopoulos, T., Heuer, H., and Bauer, K. (2000) Eur J Biochem 267, 2617-2623

68. Hussain, M. M., Tranum-Jensen, J., Noren, O., Sjostrom, H., and Christiansen, K. (1981) Biochem J 199, 179-186

69. Danielsen, E. M. (1990) Biochemistry 29, 305-308

70. Laeremans, H., Demaegdt, H., De Backer, J. P., Le, M. T., Kersemans, V., Michotte, Y., Vauquelin, G., and Vanderheyden, P. M. (2005) Biochem J 390, 351-357

71. Demaegdt, H., Smitz, L., De Backer, J. P., Le, M. T., Bauwens, M., Szemenyei, E., Toth, G., Michotte, Y., Vanderheyden, P., and Vauquelin, G. (2008) Br J Pharmacol 154, 872881

72. Matsumoto, H., Rogi, T., Yamashiro, K., Kodama, S., Tsuruoka, N., Hattori, A., Takio, K., Mizutani, S., and Tsujimoto, M. (2000) Eur J Biochem 267, 46-52

73. Ebert, J. C., and Altman, R. B. (2008) Protein Sci 17, 54-65

74. Laustsen, P. G., Vang, S., and Kristensen, T. (2001) Eur J Biochem 268, 98-104

75. De Bundel, D., Demaegdt, H., Lahoutte, T., Caveliers, V., Kersemans, K., Ceulemans, A. G., Vauquelin, G., Clinckers, R., Vanderheyden, P., Michotte, Y., and Smolders, I. (2010) J Neurochem 112, 1223-1234

76. De Bundel, D., Smolders, I., Vanderheyden, P., and Michotte, Y. (2008) CNS Neurosci Ther 14, 315-339

77. Golding, B. J., Overall, A. D., Brown, G., and Gard, P. R. (2010) Eur J Pharmacol 641, 154-159

78. Thomas, W. G., and Mendelsohn, F. A. (2003) Int J Biochem Cell Biol 35, 774-779

79. Jarvis, M. F., and Gessner, G. W. (1994) Peptides 15, 1037-1044

80. Claperon, C., Banegas-Font, I., Iturrioz, X., Rozenfeld, R., Maigret, B., and LlorensCortes, C. (2009) J Biol Chem 284, 10618-10626

81. Claperon, C., Rozenfeld, R., Iturrioz, X., Inguimbert, N., Okada, M., Roques, B., Maigret, B., and Llorens-Cortes, C. (2008) Biochem J 416, 37-46

82. Vanderheyden, P. M., Demaegdt, H., Swales, J., Lenaerts, P. J., De Backer, J. P., Vogel, L. K., and Vauquelin, G. (2006) Fundam Clin Pharmacol 20, 613-619

83. Albiston, A. L., Mustafa, T., McDowall, S. G., Mendelsohn, F. A., Lee, J., and Chai, S. Y. (2003) Trends Endocrinol Metab 14, 72-77

84. Ofner, L. D., and Hooper, N. M. (2002) Biochem J 362, 191-197

85. Ma, Z., Daquin, A., Yao, J., Rodgers, D., Thompson, M. W., and Hersh, L. B. (2003) Arch Biochem Biophys 415, 80-86

86. Iturrioz, X., Vazeux, G., Celerier, J., Corvol, P., and Llorens-Cortes, C. (2000) Biochemistry 39, 3061-3068

87. Goto, Y., Hattori, A., Mizutani, S., and Tsujimoto, M. (2007) J Biol Chem 282, 3707437081

\section{FOOTNOTES}

*This work was also supported by a grant from the National Health and Medical Research Council of Australia to S.Y.C. and M.W.P. D.B.A was an Australian Postgraduate Award Scholar and a recipient of a St. Vincent's Institute Foundation Scholarship sponsored by Colin North and Major Engineering. S.Y.C. was supported by an NHMRC Senior Research Fellowship. M.W.P. is an Australian Research Council Federation Fellow and an NHMRC Honorary Fellow.

The abbreviations used are: 1,10-PHE, 1, 10-phenanthroline; A-LAP, Adipocyte-derived; leucine aminopeptidase; Ang IV, Angiotensin IV; APA, Aminopeptidase A; APN, Aminopeptidase N; DTT, dithiothreitol; EDTA, ethylenediaminetetraacetic acid; EGTA, ethylene glycol tetraacetic 
acid; GLUT4, Glucose transporter 4; HBM, honey bee melettin; ICP-MS, Inductively Coupled Plasma Mass Spectrometry; IMAC, immobilized metal affinity chromatography; IRAP, Insulinregulated membrane aminopeptidase; L-RAP, Leukocyte-derived arginine aminopeptidase; LTA4H, Leukotriene A4 hydrolase; LVV-H7, Leu-Val-Val-hemorphin-7; MCA, 4methylcoumaryl-7-amide; MS, mass spectrometry; Nle, norleucine; SEC, size exclusion chromatography; TEV, tobacco etch virus; TOF-MS, time of flight mass-spectrometry; TRH-DE, thyrotropin-releasing hormone degrading enzyme

\section{FIGURE LEGENDS}

Fig. 1. IRAP domain structure. (A) Schematic diagram of the proposed domain boundaries and the different constructs expressed in insect cells. (B and C) Ribbon representation of the homology models of the extracellular region of IRAP based upon the crystal structures of Tricorn Interacting Factor F3 and APN respectively. Panel B is a putative model of the open state and Panel $\mathrm{C}$ the closed state of IRAP. The models are colored according to putative domains using the same coloring scheme as shown in panel $\mathrm{A}$. The $\mathrm{N}$ and $\mathrm{C}$ termini are labeled, and the approximate location of the active site is donated by a star.

Fig. 2. Kinetic and binding curves. (A) Saturation binding of ${ }^{125} \mathrm{I}^{\mathrm{N}} \mathrm{Nl}{ }^{1}$-Ang IV to construct 7 (F/A, D1-4) at three different protein concentrations. (B) Competitive binding of Ang IV in the presence and absence of $1 \mathrm{mM}$ DTT ( $\boldsymbol{\nabla}$ and $\circ$ respectively) and Nle ${ }^{1}$-Ang IV $(\boldsymbol{\Delta})$ to constructs 7 (F/A, D1-4; Panel B) and 3 (D1-2; Panel C). (D) Aminopeptidase activity of the purified constructs measured by following Leu-MCA degradation. (E) Inhibition of the aminopeptidase activity of construct 3 (D1-2) by Ang IV, concentration in nM shown for each symbol.

Fig. 3. Second zinc binding site. (A) $\mathrm{pH}$ dependence of activity and zinc binding (shown here construct 6 (JxM,D1-4)) suggest a role for histidine residues in both IRAP metal binding sites. $(n=3)$. (B) Aminopeptidase activity of the histidine mutants measured by following Leu-MCA degradation. (C and D) Proposed allosteric zinc binding site in Domain 4 with putative ligands, from left to right, His 830, His 934, His 938 and His 979 highlighted in purple. 
Table 1 Biochemical Properties of Fragments

\begin{tabular}{|c|c|c|c|c|c|c|c|}
\hline \multirow[b]{2}{*}{$\begin{array}{l}\text { Construct } \\
\text { Number } \\
\text { (domains) }\end{array}$} & \multirow[b]{2}{*}{$\begin{array}{l}\text { Oligmeriz } \\
\text { ation } \\
\mathrm{n}=2\end{array}$} & \multicolumn{2}{|c|}{$\begin{array}{c}\text { ICP-MS } \\
(\mathrm{n}=3)\end{array}$} & \multicolumn{2}{|c|}{$\begin{array}{c}\text { Radioligand } \\
\text { Saturation Binding } \\
(\mathrm{n}=3 \text { at } 3 \text { different } \\
\text { protein } \\
\text { concentrations })\end{array}$} & \multicolumn{2}{|c|}{$\begin{array}{l}\text { Radioligand } \\
\text { Competitive Binding } \\
(\mathrm{n}=3)\end{array}$} \\
\hline & & $\begin{array}{c}\text { Zn } \\
\text { content } \\
\text { (moles } \\
\text { zinc per } \\
\text { mole } \\
\text { protein) }\end{array}$ & $\begin{array}{c}\text { Zn content } \\
\text { (moles zinc } \\
\text { per mole } \\
\text { monomer) } \\
\text { in presence } \\
\text { of Ang IV }\end{array}$ & $\begin{array}{l}\mathrm{K}_{\mathrm{D}} \text { of } \\
{ }^{125} \mathrm{I}- \\
\mathrm{Nle}^{1}- \\
\text { Ang IV } \\
(\mathrm{nM})\end{array}$ & $\begin{array}{c}\mathrm{B}_{\max } \text { of } \\
{ }^{125} \mathrm{I}^{-N l e}{ }^{1}- \\
\text { Ang IV } \\
\left(\mathrm{pmol}^{125}{ }^{12}-\right. \\
\mathrm{Nle}^{1}-\mathrm{Ang} \\
\mathrm{IV} / \mathrm{pmol} \\
\text { protein) }\end{array}$ & $\begin{array}{l}\mathrm{K}_{\mathrm{I}} \text { of } \mathrm{Nle}^{1}- \\
\text { Ang IV } \\
\text { (nM) }\end{array}$ & $\begin{array}{c}\mathrm{K}_{\mathrm{I}} \text { of Ang } \\
\text { IV (nM) }\end{array}$ \\
\hline 1 (Cyto) & Monomer & $\begin{array}{l}0.03 \pm \\
0.01 *\end{array}$ & $\begin{array}{c}0.01 \pm 0.02 \\
*\end{array}$ & \multicolumn{4}{|c|}{ No detectable binding } \\
\hline $2(\mathrm{JxM}, \mathrm{D} 1-3)$ & Dimer & $\begin{array}{l}0.89 \pm \\
0.11^{*}\end{array}$ & $0.91 \pm 0.08$ & $\begin{array}{c}0.63 \pm \\
0.07\end{array}$ & $\begin{array}{c}0.87 \pm \\
0.16\end{array}$ & $1.4 \pm 0.3$ & $16 \pm 2.3$ \\
\hline $3(\mathrm{D} 1-2)$ & Dimer & $\begin{array}{l}0.92 \pm \\
0.09 *\end{array}$ & $0.89 \pm 0.17$ & $\begin{array}{c}0.57 \pm \\
0.12\end{array}$ & $\begin{array}{c}0.95 \pm \\
0.09\end{array}$ & $1.2 \pm 0.4$ & $16 \pm 1.8$ \\
\hline $4(\mathrm{D} 3-4)$ & Dimer & $\begin{array}{l}1.04 \pm \\
0.18 *\end{array}$ & $1.02 \pm 0.17$ & \multicolumn{4}{|c|}{ No detectable binding } \\
\hline 5 (D4) & Dimer & $\begin{array}{l}0.98 \pm \\
0.15 *\end{array}$ & $1.06 \pm 0.11$ & \multicolumn{4}{|c|}{ No detectable binding } \\
\hline 6 (JxM,D1-4) & Dimer & $\begin{array}{c}1.98 \pm \\
0.04\end{array}$ & $\begin{array}{c}1.12 \pm 0.18 \\
\#\end{array}$ & $\begin{array}{c}0.72 \pm \\
0.09 \\
\end{array}$ & $\begin{array}{c}1.08 \pm \\
0.05\end{array}$ & $1.3 \pm 0.3$ & $17 \pm 1.2$ \\
\hline $7(\mathrm{~F} / \mathrm{A}, \mathrm{D} 1-4)$ & Dimer & $\begin{array}{c}2.03 \pm \\
0.07\end{array}$ & $\begin{array}{c}0.98 \pm 0.09 \\
\#\end{array}$ & $\begin{array}{c}0.78 \pm \\
0.14\end{array}$ & $\begin{array}{c}0.94 \pm \\
0.08\end{array}$ & $1.5 \pm 0.2$ & $16 \pm 0.8$ \\
\hline $8(\mathrm{D} 1-4)$ & Dimer & $\begin{array}{c}2.02 \pm \\
0.06\end{array}$ & $\begin{array}{c}1.09 \pm 0.15 \\
\#\end{array}$ & $\begin{array}{c}0.76 \pm \\
0.08\end{array}$ & $\begin{array}{c}1.09 \pm \\
0.08\end{array}$ & $1.4 \pm 0.2$ & $17 \pm 1.4$ \\
\hline
\end{tabular}

$* \mathrm{p}<0.001$ compared to construct 6

$\# p<0.001$ compared to in the absence of Ang IV 
Table 2 Kinetic Constants

\begin{tabular}{|c|c|c|c|c|c|c|c|c|}
\hline $\begin{array}{l}\text { Construct } \\
\text { (aa residues) }\end{array}$ & $\begin{array}{l}K_{\mathrm{m}} \text { for } \\
\mathrm{MCA} \\
(\mu \mathrm{M}) \\
\mathrm{n}=3\end{array}$ & $\begin{array}{l}K_{\text {cat }} \\
\text { For MCA } \\
\left(\mathrm{s}^{-1}\right) \\
\mathrm{n}=3\end{array}$ & $\begin{array}{l}K_{\mathrm{m}} \text { for } \\
\text { MCA } \\
\text { with } 1 \\
\text { mM DTT } \\
(\mu \mathrm{M}) \\
\mathrm{n}=3\end{array}$ & $\begin{array}{l}K_{\text {cat }} \\
\text { For MCA } \\
\text { with 1 } \\
\text { mM DTT } \\
\left(\mathrm{s}^{-1}\right) \\
\mathrm{n}=3\end{array}$ & $\begin{array}{l}K_{\mathrm{i}} \text { Ang } \\
\mathrm{IV}(\mathrm{nM}) \\
\mathrm{n}=3\end{array}$ & $\begin{array}{l}K_{\mathrm{i}} \mathrm{LVV}- \\
\mathrm{H} 7(\mathrm{nM}) \\
\mathrm{n}=3\end{array}$ & $\begin{array}{l}K_{\mathrm{i}} \\
\text { Amastatin } \\
(\mu \mathrm{M}) \\
\mathrm{n}=3\end{array}$ & $\begin{array}{l}K_{\mathrm{i}} \\
\text { Bestatin } \\
(\mu \mathrm{M}) \\
\mathrm{n}=3\end{array}$ \\
\hline 2 (JxM,D1-3) & $\begin{array}{l}35.2 \pm \\
3.0\end{array}$ & $\begin{array}{l}0.29 \pm \\
0.05 *\end{array}$ & $\begin{array}{l}33.0 \pm \\
2.0 *\end{array}$ & $\begin{array}{l}0.22 \pm \\
0.09 *\end{array}$ & $113 \pm 3.7$ & $859 \pm 32$ & $1.2 \pm 0.12$ & $222 \pm 8.2$ \\
\hline 3 (D1-2) & $\begin{array}{l}36.7 \pm \\
1.2 \\
\end{array}$ & $\begin{array}{l}0.33 \pm \\
0.03 *\end{array}$ & $\begin{array}{l}34.5 \pm \\
1.8 * \\
\end{array}$ & $\begin{array}{l}0.34 \pm \\
0.06 *\end{array}$ & $113 \pm 3.3$ & $857 \pm 29$ & $1.3 \pm 0.11$ & $225 \pm 7.6$ \\
\hline 6 (JxM,D1-4) & $\begin{array}{l}39.7 \pm \\
0.82 \\
\end{array}$ & $\begin{array}{l}14.1 \pm \\
0.52 \\
\end{array}$ & $\begin{array}{l}25.7 \pm \\
0.73 \# \#\end{array}$ & $\begin{array}{l}21.6 \pm \\
1.6 \# \#\end{array}$ & $117 \pm 2.3$ & $847 \pm 22$ & $1.5 \pm 0.09$ & $233 \pm 7.5$ \\
\hline 7 (F/A, D1-4) & $\begin{array}{l}38.8 \pm \\
2.3\end{array}$ & $\begin{array}{l}15.2 \pm \\
0.97\end{array}$ & $\begin{array}{l}26.1 \pm \\
0.82 \# \#\end{array}$ & $\begin{array}{l}22.0 \pm \\
2.2 \# \#\end{array}$ & $117 \pm 2.8$ & $849 \pm 17$ & $1.4 \pm 0.08$ & $231 \pm 6.3$ \\
\hline 8 (D1-4) & $\begin{array}{l}38.9 \pm \\
2.0\end{array}$ & $\begin{array}{l}14.7 \pm \\
0.87\end{array}$ & $\begin{array}{l}26.1 \pm \\
0.75 \mathrm{\# \#}\end{array}$ & $\begin{array}{l}22.4 \pm \\
2.0 \# \#\end{array}$ & $118 \pm 3.2$ & $851 \pm 23$ & $1.5 \pm 0.08$ & $232 \pm 7.1$ \\
\hline $\begin{array}{l}3 \text { (D1-2) mixed } \\
\text { with }+5 \text { (D4) }\end{array}$ & $\begin{array}{l}35.8 \pm \\
1.5\end{array}$ & $\begin{array}{l}1.53 \pm \\
0.06^{*}\end{array}$ & $\begin{array}{l}30.3 \pm \\
1.44 \#\end{array}$ & $\begin{array}{l}2.5 \pm \\
0.47 *\end{array}$ & $115 \pm 2.8$ & $852 \pm 22$ & $1.4 \pm 0.11$ & $228 \pm 8.3$ \\
\hline
\end{tabular}

$* \mathrm{p}<0.001$ compared to construct 6

$\# \mathrm{p}<0.05$ compared to in the absence of DTT

$\# \# \mathrm{p}<0.001$ compared to in the absence of DTT 
A

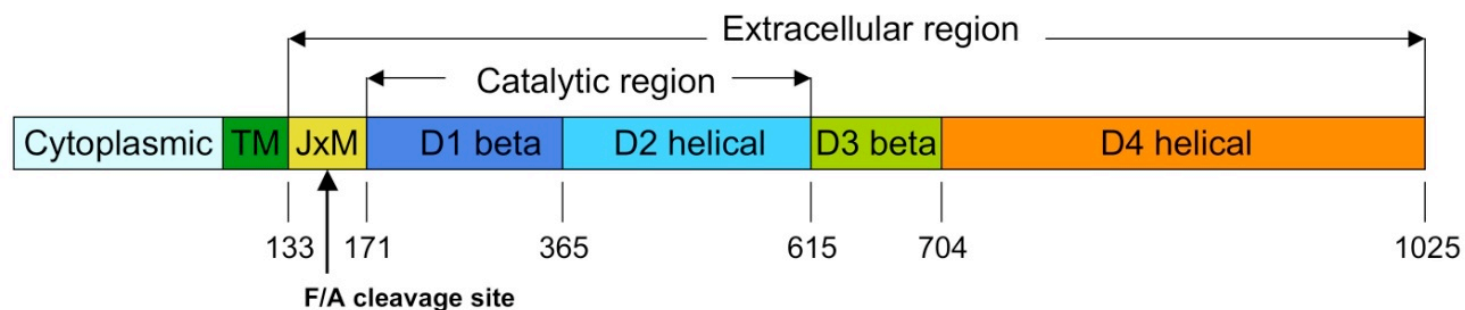

1 Cytoplasmic

2

\begin{tabular}{|l|l|l|l|}
\hline JxM & D1 beta & D2 helical & D3 beta \\
\hline
\end{tabular}

3

\begin{tabular}{|l|l|} 
D1 beta & D2 helical \\
\hline
\end{tabular}

4

D3 beta D4 helical

5

D4 helical

6

\begin{tabular}{|l|l|l|l|l}
\hline JxM & D1 beta & D2 helical & D3 beta & D4 helical
\end{tabular}

7

D1 beta

D2 helical D3 beta

D4 helical

8

\begin{tabular}{|l|l|l|l|}
\hline D1 beta & D2 helical & D3 beta & D4 helical \\
\hline
\end{tabular}

B

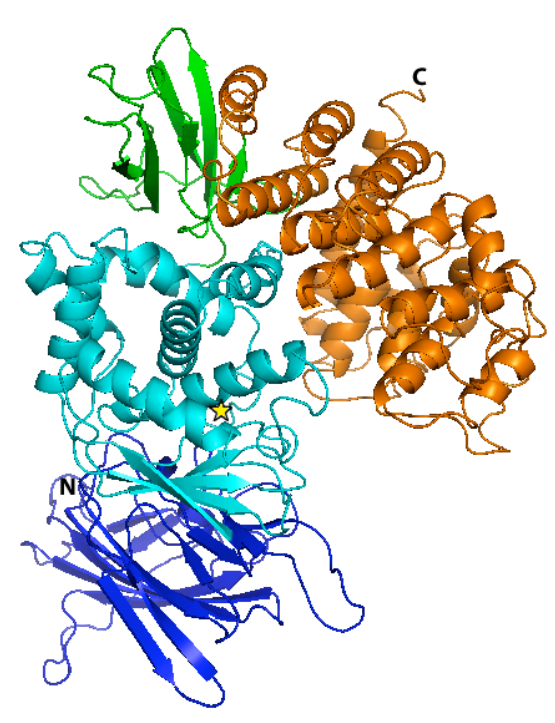

C

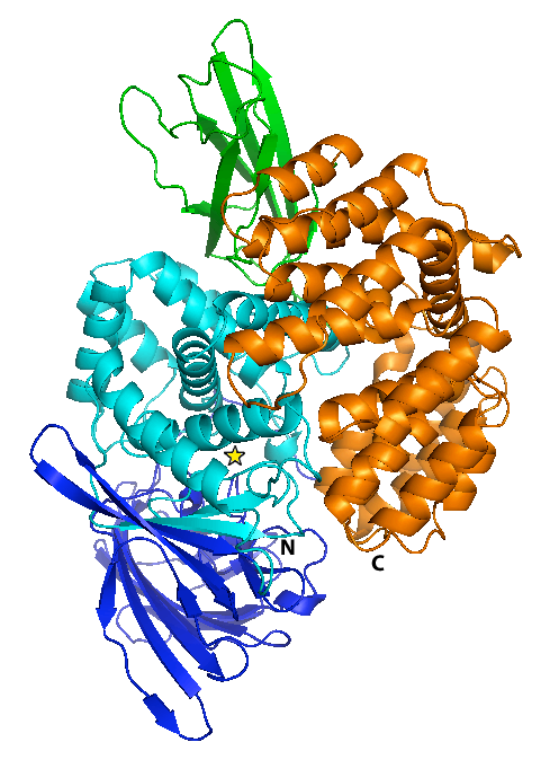

Figure 1 
A

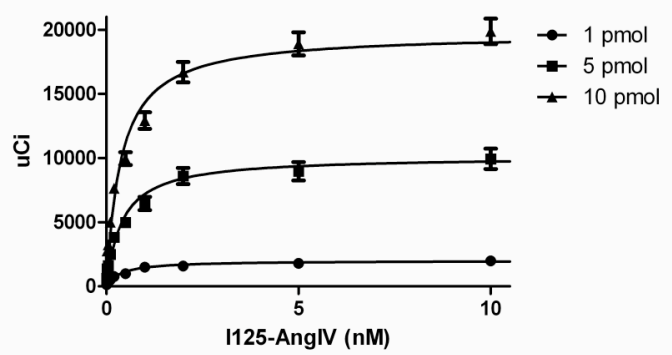

B

C
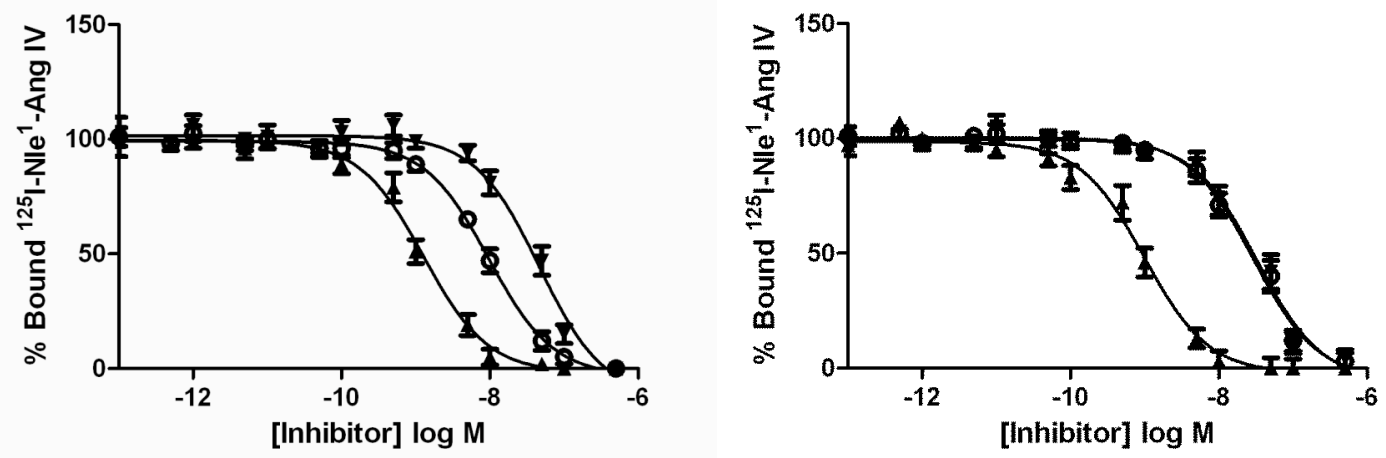

D

E
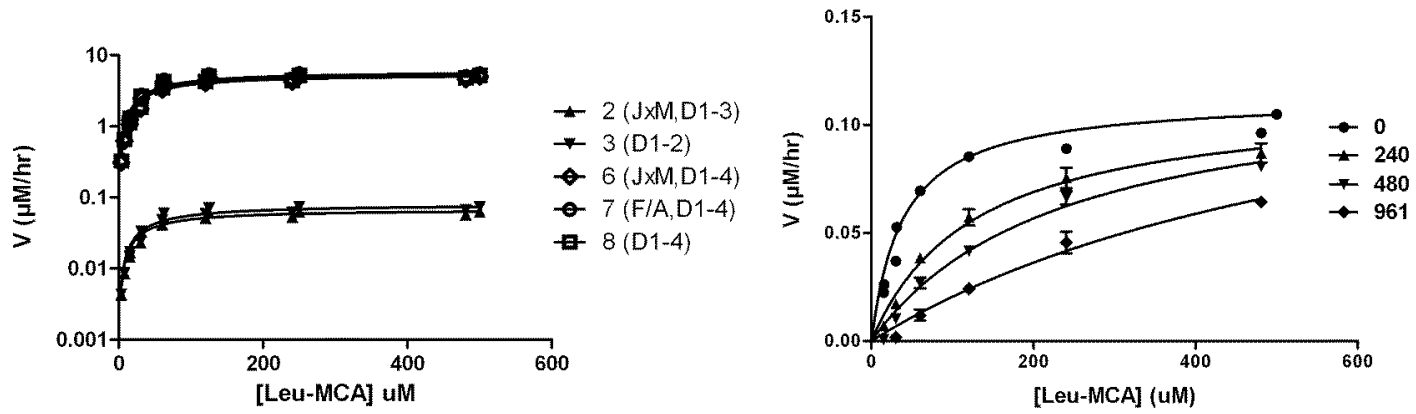

Figure 2 
A

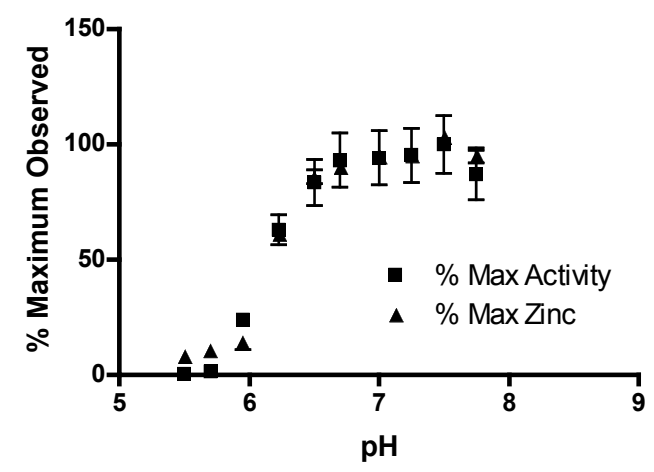

C

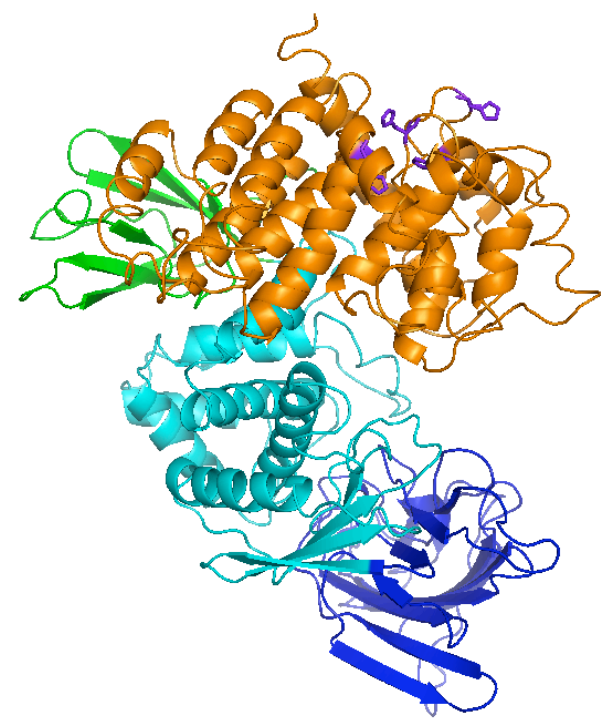

B

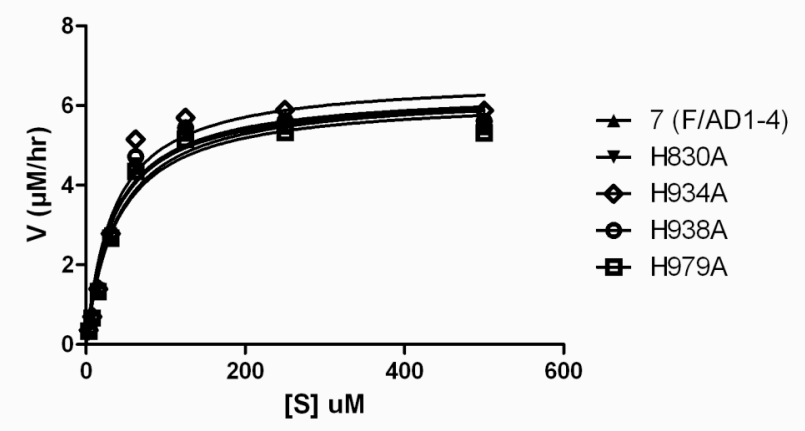

D

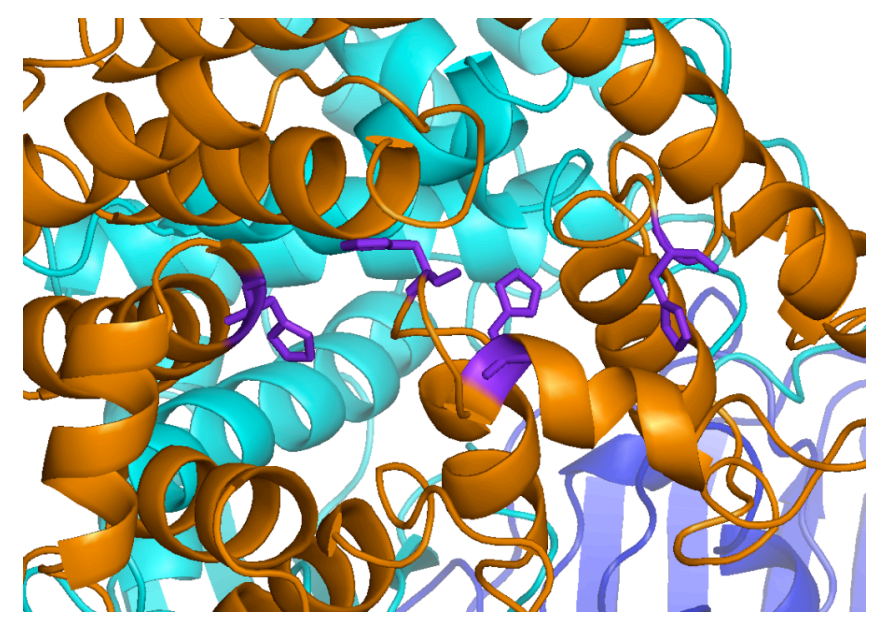

Figure 3 